Silvia Arranz Alonso1,12, Helle Marie Christensen2,12, David Díaz- Pérez ${ }^{3,12}$, Georgia Narsavage 4,12, José Miguel Padilha ${ }^{5,12}$, Juan Carlos Quijano-Campos 6,12, Andreja Sajnic ${ }^{7,12}$, Caroline Stridsman $^{8,12}$, Helmut Täub| ${ }^{9,12}$, Ann-Britt Zakrisson ${ }^{10,12}$, Marco Clari11,12

@asajnic

\title{
Do we need tailored training and development plans for European Union respiratory nurses?
}

Respiratory diseases inflict a massive health burden worldwide, affecting $>1$ billion people. COPD, asthma, acute lower respiratory tract infections, tuberculosis and lung cancer are among the most common causes of severe illness and death globally [1]. Respiratory nurses are key members of the pulmonary healthcare team caring for people in acute settings, as well as in primary care, providing a wide range of interventions from ventilation to palliative care. Their specialised roles deliver both autonomous and prescribed interventions [2-6].

Worldwide, the recognition of respiratory nurses has been effective in improving the quality of care and patients' outcomes. In Australia and the USA, the scope and role of respiratory nurses has been well defined and established for 30 years [7]. In 2017, the European Respiratory Society (ERS) documented that allied respiratory professionals (ARPs) "are involved in the prevention, diagnosis, evaluation, treatment and management of respiratory diseases" [8]; however, the role of respiratory nurses within the ARPs was not clearly delineated. In the European Union (EU) only Denmark, Finland, Iceland, Norway, Portugal, Spain, Sweden and the UK have a formal respiratory specialisation for nurses, and the competences and education levels of respiratory nurses vary from one European country to another. Currently, there is a lack of consensus on the definition, role and activities of respiratory nurses. Thus, it is challenging to understand which specialist care would be best provided by respiratory nurses, and respiratory nursing roles in joint research projects

@ERSpublications

Nurses are critical players in healthcare and should be the next profession to standardise levels of education, preparing them for an active partnership with other healthcare professionals prepared to tackle the chronic disease problem in Europe https://bit.ly/3bMR76b and educational programmes remain unclear. It is imperative that respiratory nurses themselves define the scope of respiratory nursing and replace a general description such as "nurses taking care of people with pulmonary diseases", with the clarity needed for harmonised, tailored training and development plans.

Defining and outlining the scope of practice, role and activities of respiratory nurses is of utmost importance to establish the components of advanced education for respiratory nurses. The specialisation, competences and responsibilities of respiratory nurses are still non-existent and not clearly defined in a majority of European countries (table 1) [9]. A unique curriculum for the specialisation of respiratory nurses needs to be created and implemented. Improving higher education, including basic nursing education, was the focus for development and implementation of the Bologna declaration, considered to be the most important reform to enable comparability in educational standards and quality that occurred in Europe in the past 30 years. It aimed to create a more coherent, compatible, comparable and competitive European higher education area to promote governmental inter-cooperation [10]. All countries that have signed the Bologna declaration agreed to strive for the consistency of educational systems across Europe. This agreement is especially important in respiratory nursing. Setting minimum standards of training and competence for specialties, such as in respiratory care, as well as basic nursing education, could help all European nursing schools
Cite as: Arranz Alonso S Christensen HM, Díaz-Pérez D, et al. Do we need tailored training and development plans for European Union respiratory nurses? Breathe 2020; 16: 200010

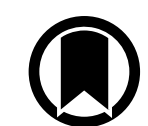

CrossMark 
Table 1 List of countries represented in ERS and, if available, level of education and title

\begin{tabular}{llll}
\hline Country & $\begin{array}{c}\text { Formal respiratory } \\
\text { specialisation for nurses }\end{array}$ & Level of education & Title \\
\hline
\end{tabular}

$\begin{array}{lll}\text { Austria } & \text { No } & \\ \text { Croatia } & \text { No } & \\ \text { Denmark } & \text { No } & \\ \text { Italy } & \text { No } & \\ \text { Portugal } & \text { Yes } & \text { Postgraduate, vertical } \\ \text { Spain } & \text { Yes } & \text { Postgraduate, horizontal } \\ \text { Sweden } & \text { Yes } & \text { Postgraduate, horizontal } \\ \text { UK } & \text { Yes } & \text { Postgraduate, vertical }\end{array}$

A master's degree in rehabilitation nursing
Expert in respiratory nursing care
Asthma, allergy and COPD nurses
Advanced nurse practitioner in respiratory care

These results have been collected through a survey conducted in December 2019 among ERS Nurses Group 09.03 members.

to implement a coherent curriculum higher nursing education [11]. Initially, a consensus must be found on whether respiratory nurses' education should be an advanced course $(<1$ year full-time post-graduate), a diploma (1 year full-time postgraduate) or a master's degree (2 years full-time post-graduate).

Respiratory nursing specialisations and specialised courses are available, but not consistently across Europe. Additionally, the effectiveness of programmes that improve graduate nurse transition to the workforce in terms of contributing to staff retention has not been proven $[9,12]$. The transition of nurses to advanced practice has, however, been shown to be a critical strategy in attracting nurses to specialty areas [9, 13]. Current Transition to Specialty Practice (TSP) programmes do provide a structured, supported practice for nurses entering a specific nursing area [9] but these TSP programmes have no consistent framework available to guide their development or delivery. As a result, there are significant variations in the way TSP programmes are delivered [14]. Moreover, upon completion of the specialisation, levels of competencies also differ from one country to another [9, 15-17].

Recognisably, higher levels of nursing education and training are influenced by national education systems, statutory and regulatory processes, and by professional groups in each country [18]. Therefore, addressing these issues could best be accomplished by bringing together academic and clinical expert nurses from the respiratory field to form a working group capable of tackling these challenges. The main goal of this group would be to define a scope of practice, a curricular framework and a platform to share educational resources with other EU countries [9, 19, 20]. This group could provide opportunities for nurses to establish closer links with their European colleagues across a spectrum of clinical practice, management, and research to raise the awareness and benefits of the respiratory nurse specialist role [21].

The ERS Nurses Group 09.03 should lead this working group, and provide support and links to all nurses, stakeholders and patients that wish to contribute to the recognition and advancement of respiratory nurses. The role of specialised respiratory nurses needs to be recognised by healthcare systems in all EU countries. The EU and national regulators must be led to recognise that an evolution of quality standards and harmonisation of respiratory specialist nurse education is critical to improving care for patients with respiratory diseases. Thanks to advances in diagnosis and treatment, people with respiratory diseases potentially have a longer life expectancy with better quality of life. Tailored training and development of respiratory specialist nurses could be the solution to realising this potential. Other allied respiratory professions have documented how harmonised roles and education are at the forefront of high quality and safe care provision as well as enhanced quality of life for patients [8]. Nurses are critical players in healthcare and should be the next profession to standardise levels of education, preparing them for an active partnership with other healthcare professionals prepared to tackle the chronic disease problem in Europe.

\section{Affiliations}

Silvia Arranz Alonso1,12, Helle Marie Christensen²,12, David Díaz- Pérez ${ }^{3,12}$, Georgia Narsavage ${ }^{4,12}$, José Miguel Padilha5,12, Juan Carlos Quijano-Campos ${ }^{6,12}$, Andreja Sajnic ${ }^{7,12}$, Caroline Stridsman ${ }^{8,12}$, Helmut Täub|9,12, Ann-Britt Zakrisson ${ }^{10,12}$, Marco Clari11,12

${ }^{1}$ Nursing Development Foundation (FUDEN), Madrid, Spain. ${ }^{2}$ Dept of Respiratory Medicine, Odense University Hospital, Odense, Denmark. ${ }^{3}$ Pneumology and Thoracic Surgery Service, University Hospital Nuestra Señora de la Candelaria (HUNSC), Santa Cruz de Tenerife, Spain. ${ }^{4}$ School of Nursing, West Virginia University, Morgantown, 
WV, USA. ${ }^{5}$ Nursing School of Porto, CINTESIS-Tech4edusim, Porto, Portugal. ${ }^{6}$ Research and Development, Royal Papworth Hospital NHS Foundation Trust, Cambridge, UK. ${ }^{7}$ Dept of Respiratory Diseases Jordanovac, University Hospital Center, Zagreb, Croatia. ${ }^{8}$ Dept of Public Health and Clinical Medicine, Section of Medicine, Umeå University, Umeå, Sweden. ${ }^{9}$ Dept for Pulmology, Public Hochzirl-Natters Hospital, Natters, Austria. ${ }^{10}$ University Healthcare Research Center, Örebro University, Örebro, Sweden. ${ }^{11}$ Dept of Public Health and Pediatrics, University of Torino, Turin, Italy. ${ }^{12} \mathrm{All}$ authors contributed equally.

\section{Acknowledgments}

The authors want to thank the ERS Nurses Group 09.03 for contributing to the advancement of European respiratory nurses. In addition, Dr Luciani helped in providing writing support. We want to thank Prof. Mario Režić for his editorial support to complete this paper.

\section{Author contributions}

All authors conceived and designed this article. Administrative support was provided by Andreja Sajnic. All authors analysed and interpreted the data, and wrote and gave final approval of the manuscript.

\section{Conflict of interest}

None declared.

\section{References}

1. Strachan D, Gupta RA, Limb E. The burden of lung disease. In: Gibson GJ, Loddenkemper R, Sibille Y, et al. eds. European Lung White Book. 2nd Edn. Sheffield, European Respiratory Society, 2013; pp. 2-15.

2. Rafferty $S$, Elborn $S$. The role of the respiratory nurse specialist. Clin Pulm Med 2004; 11: 228-236.

3. Vrijhoef HJ, Diederiks JP, Spreeuwenberg C. Effects on quality of care for patients with NIDDM or COPD when the specialised nurse has a central role: a literature review. Patient Educ Couns 2000; 41: 243-250.

4. Fletcher MJ, Dahl BH. Expanding nurse practice in COPD: is it key to providing high quality, effective and safe patient care? Prim Care Respir J 2013; 22: 230-233.

5. Considine J. The role of nurses in preventing adverse events related to respiratory dysfunction: literature review. J Adv Nurs 2005; 49: 624-633.

6 . Vincent E, Sewell L. The role of the nurse in pulmonary rehabilitation. Nurs Times 2014; 110: 16-18.

7. Hanley MV, Abraham M, Maibusch R, et al. Standards of nursing care for adult patients with pulmonary dysfunction. Am Rev Respir Dis 1991; 144: 231-236.

8. Troosters T, Burge G, Steenbruggen I. Allied respiratory professionals. In: Gibson GJ, Loddenkemper R, Sibille Y, et al. eds. European Lung White Book. 2nd Edn. Sheffield, European Respiratory Society, 2013; pp. 382-391.

9. Boyle M, Butcher R, Conyers V, et al. Transition to intensive care nursing: establishing a starting point. Aust Crit Care 2008; 21: 190-198.

10. Palese A, Zabalegui A, Sigurdardottir AK, et al. Bologna process, more or less: nursing education in the European economic area: a discussion paper. Int J Nurs Educ Scholarsh 2014; 11: 63-73.
11. Humar L, Sansoni J. Bologna process and basic nursing education in 21 European countries. Ann lg 2017; 29: 561-571.

12. Levett-Jones T, FitzGerald $M$. A review of graduate nurse transition programs in Australia. Aust J Adv Nurs 2005; 23: $40-45$.

13. Heath P. The National Review of Nursing and Nursing Education 2002 - our duty of care. Canberra, Commonwealth of Australia, 2002.

14. Morphet J, Plummer V, Kent B, et al. A framework for transition to specialty practice programs. J Adv Nurs 2017; 73: 1970-1981.

15. Aitken LM, Currey J, Marshall A, et al. The diversity of critical care nursing education in Australian universities. Aust Crit Care 2006; 19: 46-52.

16. Zabalegui A, Macia L, Márquez J, et al. Changes in nursing education in the European Union. J Nurs Scholarsh 2006; 38: 114-118.

17. Arranz SA, Cordero SP. A qualitative hermeneutic phenomenological research among respiratory nurses (Rsn) in Spain to understand the lived experience of their profession. Eur Respir J 2019; 54: Suppl. 63, PA1261.

18. German Millberg L, Berg L, Lindström I, et al. Tensions related to implementation of postgraduate degree projects in specialist nursing education. Nurse Educ Today 2011; 31: 283-288.

19. Collins S, Hewer I. The impact of the Bologna process on nursing higher education in Europe: a review. Int J Nurs Stud 2014; 51: 150-156.

20. Aiken LH, Clarke SP, Cheung RB, et al. Educational levels of hospital nurses and surgical patient mortality. JAMA 2003; 290: 1617-1623.

21. Davies R. The Bologna process: The quiet revolution in higher education. Nurse Educ Today 2008; 28: 935-942. 